\title{
Measurement of the Maximum Bite Force in the Natural Dentition with a Gnathodynamometer
}

\author{
Nickolay Apostolov, Ivan Chakalov, Todor Drajev \\ Department of Prosthetic Dentistry, Faculty of Dental \\ Medicine, Medical University - Sofia, Bulgaria
}

\begin{abstract}
The aim of the present study is to measure the maximum bite force (MBF) in the natural dentition with the help of a force-measurement device - gnathodynamometer, designed and constructed specially for the purpose of the study. Materials and methods: 80 students from FDM-Sofia, aged between 20 and 32, were tested. Each student was given instructions about the study and its method, and the tests were carried out thereafter. The tip of the force-measuring tensometric module of the gnathodynamometer was first placed in the area of the frontal teeth and the patient was asked to bite firmly, until the first signs of pain were felt. Afterwards the device was placed in the area of the first left molars and the first right molars. The whole study was repeated three times. The results were recorded in a specially designed table. Results: The clinical study indicated that the maximum bite force is significantly greater in male students as compared to female students. This phenomenon was observed during measurements in the three regions - frontal, left molars and right molars. It was found that in both genders the maximum bite force is greater in the distal regions as compared to the maximum bite force in the frontal region. Conclusion: Our research proves that the maximum bite force in male subjects is greater than that in female subjects. The values in the area of the left and right molars are almost equal, while the values in the molar regions are about 3 times greater than those in the frontal region
\end{abstract}

Key words: maximum bite force, gnathodynamometer

\section{Introduction}

The maximum bite force is a basic parameter related to the functional state of the masticatory system (1).This is the maximum force which a human can reach while clenching their teeth, without the 
occurrence of pain in the periodontal tissues (2). According to Black, the maximum chewing force is about $390 \mathrm{~kg}$, and the maximum bite force in people with intact natural dentition rarely exceeds $50-60 \mathrm{~kg}$ (3). The maximum bite force reaches its highest value in the area of the molars and decreases in the frontal area by $1 / 3$ to $1 / 4$ (4). According to Craig and Powers, cited by Anastassov, the mean value of the chewing forces in adults is $57 \mathrm{~kg}$ in the area of the molars and about $16 \mathrm{~kg}$ in the area of the incisors (5). The higher value in the molar region is explained by the greater periodontal area of the distal teeth in the natural dentition (6). The state of the dentition also has an influence on the maximum bite force - the type of the prosthetic construction, the number of natural teeth and the state of their periodontium (7). It is considered that generally the values of the maximum bite force in men are greater than in women and tend to decrease with age (8).

The maximum bite force is measured with various types of force-measurement devices, called gnathodynamometers, the first of which was developed in 1681 by Bordelli cited by Ortuğ, while in 1893 Black constructed his own force-measurement device and did research on the forces acting in the mouth (9). In the 20 s of the $20^{\text {th }}$ century Haber, cited by Filchev, designed a gnathodynamometer for determining the normal threshold of resistance of the periodontium (3). Electronic measurement devices with the capacity to measure forces between 50 and $800 \mathrm{~N}$ can also be used for determining the maximum bite strength. Another option is the combination of an electric device and piezoelectric film, whose deformation under the action of the chewing forces can be detected and measured by a computer (10).

According to Dean, cited by Filchev, the mean values of the maximum bite strength in the molar region are $490 \mathrm{~N}$ in men and $402 \mathrm{~N}$ in women with a natural dentition (3). In a study of 63 women and 59 men Bakke measured mean values of the maximum bite force of $522 \mathrm{~N}$ in men and $441 \mathrm{~N}$ in women (11). According to Osborne the maximum bite force in the frontal area is about $190 \mathrm{~N}$ in men and $50 \mathrm{~N}$ in women (12).

\section{Aim}

The aim of the present study is to measure the maximum bite force (MBF) in the natural dentition with a force-measurement device - gnathodynamometer, designed and constructed specially for the purpose of the study.

\section{Materials and methods}

All 80 students (35 males and 45 females) were selected randomly during the hands-on classes in Propedeutics of Prosthetic Dentistry in the period between April 2013 and May 2014. The participants in the study were informed about its purpose and gave their consent to take part in it.

A force-measurement device - gnathodynamometer * was constructed for the purpose of the study (Fig. 1). The device comprises a programmable indicator GD500.1 with an accuracy class 0,1 ; tensometric force-measuring module $500 \mathrm{~N}$ with a range of measurement between 0 to $500(650) \mathrm{N}$; electric charger. 
Figure 1. Gnathodynamometric system GD500.1

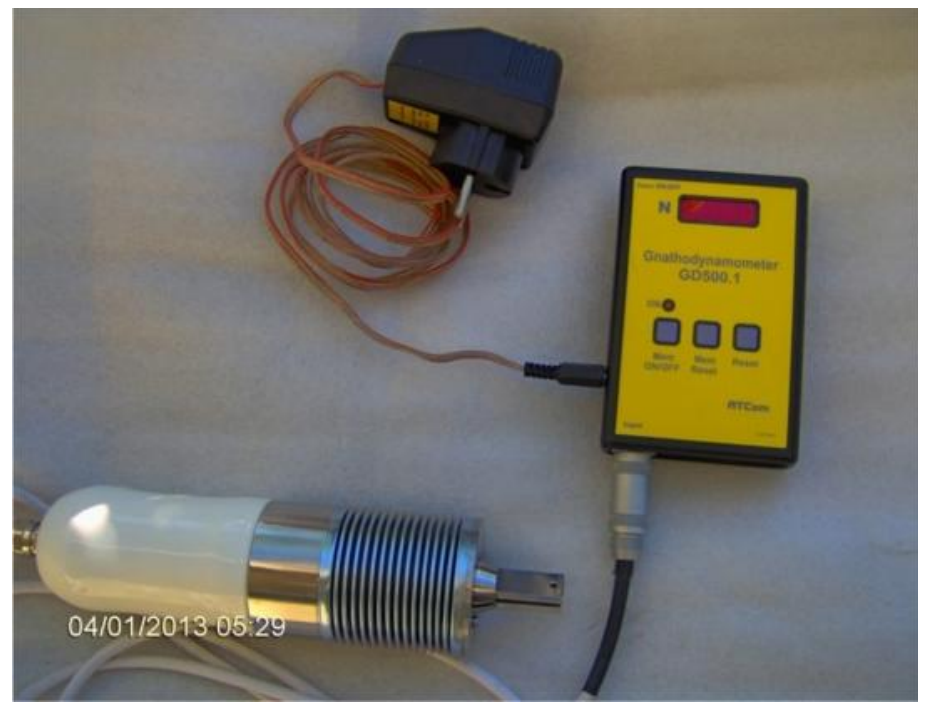

Each participant was informed in advance of the method of the study. It was explained that the biting on the force-measuring tensometric module should continue only until first signs of pain are felt. The forcemeasuring tensometric module was disinfected with Desident spray before each test. It was placed first in the area of the two central incisors and each patient was asked to clench their teeth firmly, first until a contact with the tensometric module was achieved and then - until the first feeling of pain occurred in the periodontal tissues. The results were recorded in a specially designed table (Fig. 2). Afterwards the forcemeasuring module was moved to the area of the first left molars for repeating the test in this region. The data was recorded in the table and the same test was carried out in the right molar area. The test was repeated 3 times in each patient following the same sequence - frontal area, left first molars, and right first molars.

The data obtained in the study was recorded and statistically analyzed withl BM SPSS Statistics 22.0. P 0.05 was set as a significance level, at which the null hypothesis would be rejected.

Results

The results from the statistical analysis of the data obtained from the measurement of the maximum bite force in the natural dentition with a gnathodynamometer are presented in Table 1. 
Table 1. Comparative analysis of the maximum bite force according to the area of measurement and the gender of the patients

\begin{tabular}{|c|c|c|c|c|c|c|c|c|c|c|c|}
\hline \multirow[b]{2}{*}{ er } & \multicolumn{5}{|c|}{ Men } & \multicolumn{5}{|c|}{ Women } & \multirow{2}{*}{$P$} \\
\hline & $\mathrm{N}$ & $\bar{X}$ & SD & Min & Max & $\mathrm{N}$ & $\bar{X}$ & $\mathrm{SD}$ & Min & Max & \\
\hline Frontal & $\begin{array}{l}3 \\
5\end{array}$ & $\begin{array}{l}138,22 \\
a\end{array}$ & 44,24 & 33,00 & $\begin{array}{l}228,5 \\
0\end{array}$ & 45 & $97,08^{\mathrm{a}}$ & $\begin{array}{l}38,5 \\
5\end{array}$ & $\begin{array}{l}37,0 \\
0\end{array}$ & $\begin{array}{l}198,3 \\
3\end{array}$ & $\begin{array}{l}<0,00 \\
1\end{array}$ \\
\hline Left molars & $\begin{array}{l}3 \\
5\end{array}$ & $\begin{array}{l}355,27 \\
b\end{array}$ & $\begin{array}{c}121,0 \\
7\end{array}$ & $\begin{array}{c}109,6 \\
7\end{array}$ & $\begin{array}{l}544,6 \\
7\end{array}$ & 45 & $\underset{\mathrm{b}}{218,63}$ & $\begin{array}{l}88,0 \\
3\end{array}$ & $\begin{array}{l}67,6 \\
7\end{array}$ & $\begin{array}{l}443,0 \\
0\end{array}$ & $\begin{array}{l}<0,00 \\
1\end{array}$ \\
\hline Right molars & $\begin{array}{l}3 \\
5\end{array}$ & $\begin{array}{l}353,07 \\
b\end{array}$ & $\begin{array}{c}126,7 \\
0\end{array}$ & $\begin{array}{c}106,6 \\
7\end{array}$ & $\begin{array}{l}513,3 \\
3\end{array}$ & 45 & $\underset{b}{218,29}$ & $\begin{array}{l}90,7 \\
2\end{array}$ & $\begin{array}{l}78,3 \\
3\end{array}$ & $\begin{array}{l}455,3 \\
3\end{array}$ & $\begin{array}{l}<0,00 \\
1\end{array}$ \\
\hline
\end{tabular}

*the same letters in the columns indicate absence of significant difference, while the different letters presence of such difference $(p<0,05)$

The data shows that the maximum bite force is significantly greater in males as compared to females. In males the maximum bite force in the frontal area has a mean value of $138 \mathrm{~N}$ (and a minimum value of $33 \mathrm{~N}$ ), while in females the mean value is $97 \mathrm{~N}$ (minimum value $-37 \mathrm{~N}$ ). The maximum values are $228 \mathrm{~N}$ in men and $198 \mathrm{~N}$ in women.

The differences are even greater in the molar regions. In the left molar area the mean value of the maximum bite force is around $355 \mathrm{~N}$ in men (while the minimum value is $110 \mathrm{~N}$ ) and in women it is $218 \mathrm{~N}$ (minimum value $-88 \mathrm{~N}$ ). The maximum values are $554 \mathrm{~N}$ for men and $443 \mathrm{~N}$ for women.

In the right molar area the mean value of the maximum bite force is around $353 \mathrm{~N}$ in men (with a minimum value of $107 \mathrm{~N}$ ), while in women it is $218 \mathrm{~N}$ (with minimum value of $78 \mathrm{~N}$ ). The maximum values are $513 \mathrm{~N}$ in men and $455 \mathrm{~N}$ in women.

These results indicate that the values in the area of the left and right molars are almost equal while the values in the molar regions are about 3 times greater than those in the frontal region.

\section{Discussion}

The results in Table 1 show that the data obtained in our tests is similar to that obtained by other authors who have been studying the maximum bite force before in populations other than Bulgarian. According to our studies the maximum bite force in the distal areas is about 3 times greater than the one in the frontal area, while according to Helkimo (4) it decreases by $1 / 3$ up to $1 / 4$ in the frontal region. According to Bakke, Dean, Osborne and Sargentini the maximum bite force in men is greater than in women $(3,8,12,13)$. Our study confirms these results.

The values obtained by Dean (7) and Bakke (11) regarding the maximum bite force in the molar regions are greater than those obtained in our study. According to them the mean values in men are between 490 and $520 \mathrm{~N}$ (355N according to our study), while in women they are $400-440 \mathrm{~N}$ ( $220 \mathrm{~N}$ in our study). There 
are differences in the results obtained by Osborne (12) regarding the mean value of the maximum bite force in the frontal region. According to him it is $190 \mathrm{~N}$ in men (as compared to $140 \mathrm{~N}$ in our study), and $50 \mathrm{~N}$ in women ( $98 \mathrm{~N}$ according to our study).

Patient:

Age:

Natural dentition:

Table 2. Table for recording the data obtained from the gnathodynamometric study

\begin{tabular}{|l|l|l|l|}
\hline Test number & Frontal area & Left molars & Right molars \\
\hline 1 & & & \\
\hline 2 & & & \\
\hline 3 & & & \\
\hline
\end{tabular}

*The gnathodynamometric system was developed with the help of eng. Al. Tatsov and Dr. T. Drajev

\section{Conclusion}

Our research proves that the maximum bite force in male subjects is greater than that in female subjects. The values in the area of the left and right molars are almost equal, while the values in the molar regions are about 3 times greater than those in the frontal region.

\section{References:}

1. Floystrand F, Kleven E, Gudbrand O. A novel miniature bite force recorder and its application. Acta Odontol. Scand 1982;40:4: 209-214.

2. Helkimo E, Heath MR, Jiffry MT. Factors contributing to mastication: an investigation using 4 different foods. J. Oral. Rehabil1983;10:5:431.

3. Filchev A, Ralev R. Preclinics of prosthetic dentistry, Sofia, 2007;7-16.

4. Helkimo E, Carlsson G,Carmell Y. Bite force in patients with functional disturbances of masticatory system. J. Oral Rehabil 1975;2:397.

5. Anastassov I, Yoshida J, Dragev T. Textbook of dental materials. Sofia, Sofia Smile Center 2013;36-63.

6. Bojanov B. Electrotensiometric functional study of the periodontal pain threshold. Stomatology1969;5:351-358.

7. Dean JS, Trockmorton SG, Ellis EE, et al. A preliminary study of maximum voluntry bite force and jaw muscle efficiency in preorthodontic surgery patients. J Oral Maxilofac Surg 1992;50:12841288. 
8. Sargentini, A. Theorie und Praxis der totalen gaumenfreien Prothese. Schw.Mschr.Zahnk., $1949 ; 10$.

9. Ortuğ G. A new device for measuring mastication force. Ann Anat2002;184:393-396.

10. Van Aken AA, De Baat C, Van Rossum GM, et al. Prosthetic condition and satisfaction with dentures. Ned. Tijdcher. Tandheelkd 1995;102:1:12-14.

11. Bakke M, Halm B, Jensen L, et al. Unilateral isometric bite force in eight 68-year-old women and men related to occlusal factors. Scand J Dent Res 1990;98:149-158.

12. Osborne JW, Mao J. A thin bite force transducer with three-dimensional capabilities.Archives of Oral Biology 1993;38:139-144.

13. Carlsson GE. Bite force and chewing efficiency. Frontiers of Oral Physiology, Karger,Basel 1974;1,265-292.

\section{Corresponding author:}

Nickolay Apostolov,

Department of Prosthetic Dentistry, Faculty of Dental Medicine, Medical University - Sofia,

Georgi Sofiyski blvd., 1431 Sofia, Bulgaria; e-mail: nickogl@abv.bg tel.+359 885247283 